Experimental and Kinetic Modeling Study of Extinction and Ignition of Methyl Decanoate in Laminar Nonpremixed Flows

Kalyanasundaram Seshadri, Tianfeng Lu, Olivier Herbinet, Stefan Humer, Ulrich Niemann, William J. Pitz, Chung K. Law

January 10, 2008

Thirty-Second International Symposium on Combustion Montreal, Canada August 3, 2008 through August 8, 2008 
This document was prepared as an account of work sponsored by an agency of the United States government. Neither the United States government nor Lawrence Livermore National Security, LLC, nor any of their employees makes any warranty, expressed or implied, or assumes any legal liability or responsibility for the accuracy, completeness, or usefulness of any information, apparatus, product, or process disclosed, or represents that its use would not infringe privately owned rights. Reference herein to any specific commercial product, process, or service by trade name, trademark, manufacturer, or otherwise does not necessarily constitute or imply its endorsement, recommendation, or favoring by the United States government or Lawrence Livermore National Security, LLC. The views and opinions of authors expressed herein do not necessarily state or reflect those of the United States government or Lawrence Livermore National Security, LLC, and shall not be used for advertising or product endorsement purposes. 
Elsevier Editorial System(tm) for Proceedings of the Combustion Institute Manuscript Draft

Manuscript Number:

Title: Experimental and Kinetic Modeling Study of Extinction and Ignition of Methyl Decanoate in Laminar Nonpremixed Flows

Article Type: Research Paper

Keywords: biodiesel, methyl decanoate, surrogate, non premixed, chemical kinetic mechanism

Corresponding Author: Professor Kalyanasundaram Seshadri, Ph.D

Corresponding Author's Institution: University of California at San Diego

First Author: Kalyanasundaram Seshadri, Ph.D

Order of Authors: Kalyanasundaram Seshadri, Ph.D; Tianfeng Lu; Olivier Herbinet, Ph.D; Stefan Humer, Ph.D; Ulrich Niemann; William J Pitz, Ph.D; Chung K Law, Ph.D

Abstract: Methyl decanoate is a large methyl ester that can be used as a surrogate for biodiesel. In this experimental and computational study, the combustion of methyl decanoate is investigated in nonpremixed, nonuniform flows. Experiments are performed employing the counterflow configuration with a fuel stream made up of vaporized methyl decanoate and nitrogen, and an oxidizer stream of air. The mass fraction of fuel in the fuel stream is measured as a function of the strain rate at extinction, and critical conditions of ignition are measured in terms of the temperature of the oxidizer stream as a function of the strain rate. It is not possible to use a fully detailed mechanism for methyl decanoate to simulate the counterflow flames because the number of species and reactions is too large to employ with current flame codes and computer resources. Therefore a skeletal mechanism was deduced from a detailed mechanism of 8555 elementary reactions and 3036 species using "directed relation graph" method. This skeletal mechanism has only 713 elementary reactions and 125 species. Critical conditions of ignition were calculated using this skeletal mechanism and are found to agree well with experimental data. The predicted strain rate at extinction is found to be lower than the measurements. In general, the methyl decanoate mechanism provides a realistic kinetic tool for simulation of biodiesel fuels. 



\title{
Experimental and Kinetic Modeling Study of Extinction and Ignition of Methyl Decanoate in Laminar Nonpremixed Flows
}

\author{
Kalyanasundaram Seshadri ${ }^{(1)}$, Tianfeng Lu ${ }^{(2)}$, Olivier Herbinet ${ }^{(3)}$, Stefan Humer ${ }^{(1)}$, Ulrich
} Niemann ${ }^{(1)}$, William J. Pitz ${ }^{(3)}$, and Chung K. Law ${ }^{(2)}$

(1) Department of Mechanical and Aerospace Engineering, University of California at San Diego, La Jolla, California 92093-0411, USA,

${ }^{(2)}$ Department of Mechanical and Aerospace Engineering, Princeton University, Princeton, NJ 08544, USA,

${ }^{(3)}$ Lawrence Livermore National Laboratory, Livermore, California 94550, USA.

Corresponding author:

K. Seshadri,

Department of Mechanical and Aerospace Engineering,

University of California at San Diego,

La Jolla, California 92093-0411,

Phone: (858) 534-4876. Fax: (858) 534-5354,

email: seshadri@ucsd.edu

- Preferred colloquium topic: Laminar Flames.

- Keywords: biodiesel, methyl decanoate, surrogate, non premixed, chemical kinetic mechanism

- Word-Length

- Length: 7-1/3 pages (method 2)

- Preferred presentation: Oral

Thirty-Second International Symposium on Combustion

Mc Gill University,

Montreal, Canada

August 3-8, 2008 


\title{
Experimental and Kinetic Modeling Study of Extinction and Ignition of Methyl Decanoate in Laminar Nonpremixed Flows
}

\begin{abstract}
Methyl decanoate is a large methyl ester that can be used as a surrogate for biodiesel. In this experimental and computational study, the combustion of methyl decanoate is investigated in nonpremixed, nonuniform flows. Experiments are performed employing the counterflow configuration with a fuel stream made up of vaporized methyl decanoate and nitrogen, and an oxidizer stream of air. The mass fraction of fuel in the fuel stream is measured as a function of the strain rate at extinction, and critical conditions of ignition are measured in terms of the temperature of the oxidizer stream as a function of the strain rate. It is not possible to use a fully detailed mechanism for methyl decanoate to simulate the counterflow flames because the number of species and reactions is too large to employ with current flame codes and computer resources. Therefore a skeletal mechanism was deduced from a detailed mechanism of 8555 elementary reactions and 3036 species using "directed relation graph" method. This skeletal mechanism has only 713 elementary reactions and 125 species. Critical conditions of ignition were calculated using this skeletal mechanism and are found to agree well with experimental data. The predicted strain rate at extinction is found to be lower than the measurements. In general, the methyl decanoate mechanism provides a realistic kinetic tool for simulation of biodiesel fuels.
\end{abstract}

\section{Introduction}

There is considerable interest in understanding the combustion of biodiesel because it is recognized as an alternative and renewable fuel. It is produced from virgin or used vegetable oils and animal 
fats through various chemical processes. The most common is transesterification. The components in biodiesel are generally methyl, ethyl, or higher alkyl esters, depending on the alcohol used in the transesterification process. In the United States, biodiesel is generally made from soybean seeds. Biodiesel from soybean seeds consists of five methyl esters. Their proportions by volume are methyl palmitate $(11 \%)$, methyl sterate $(4 \%)$ methyl oleate $(17 \%)$, methyl linoleate $(67 \%)$, methyl linolenate $(1 \%)$. These same methyl esters are found in biodiesel derived from other vegetable oils such as rapeseed oil, but the proportions differ. Methyl esters in particular methyl butanoate $(n-$ $\left.\mathrm{C}_{3} \mathrm{H}_{7} \mathrm{C}(=\mathrm{O}) \mathrm{OCH}_{3}\right)$ and methyl decanoate $\left(n-\mathrm{C}_{9} \mathrm{H}_{19} \mathrm{C}(=\mathrm{O}) \mathrm{OCH}_{3}\right)$ have been proposed as possible surrogates for biodiesel [1-7]. The present study is focused on combustion of methyl decanoate.

Biodiesel fuels are generally very large molecules that challenge the capabilities of kinetic modeling. As a result, past research in this area has followed two major paths. Experiments and kinetic modeling of much smaller methyl esters have addressed the special features of methyl ester oxidation, and combustion of large biofuels has been studied by assuming that large methyl esters can be approximated as being fundamentally the same as large normal alkanes. The largest methyl ester that has been studied kinetically is methyl butanoate, with a chain of only 4 carbon atoms connected to the methyl ester group. Kinetic modeling of methyl butanoate has concluded that this fuel reproduces kinetic features of the oxidation of the methyl ester, but does a poor job of reproducing kinetic features of diesel fuels with their chains of 16 - 18 carbon atoms. Other studies have used kinetic models for normal alkanes as large as $n$-hexadecane to simulate the combustion of the large methyl ester molecules in actual biodiesel fuels. Recently Herbinet et. al. [7] developed a reliable kinetic model for describing the combustion of methyl decanoate, with a chain of 10 carbon atoms with a methyl ester group attached. Methyl decanoate reacts in a manner that is much closer to actual 
biodiesel fuel than methyl butanoate, including both early production of $\mathrm{CO}_{2}$ from the methyl ester group and burning in a manner very similar to biodiesel derived from rapeseed based methyl esters.

Previous studies of ignition and combustion of methyl decanoate have been focused on premixed systems [5-7]. The present study considers combustion of methyl decanoate in nonpremixed, aerodynamically strained flows. It is important to examine combustion characteristics and validate chemical-kinetic models under conditions of fluid dynamic strain because these conditions are often found in internal combustion engines where there are high rates of swirl. Extinction characteristics are examined because flame extinction in high strained flows is an important problem in gas turbine engines. Ignition under aerodynamic strain is relevant because fuel/air mixtures must be ignited in flows in internal combustion engines under these conditions. Experiments are carried out employing the counterflow configuration. Critical conditions of extinction and ignition are measured. The chemical-kinetic mechanism for methyl decanoate is tested by comparing predictions of this mechanism with experimental data.

\section{Experimental Apparatus and Procedures}

Figure 1 shows a schematic illustration of the counterflow system. Prevaporized fuel mixed with nitrogen is injected from the fuel-duct, and a stream of air is injected from the oxidizer-duct. The exit of the fuel-duct is called the fuel boundary, and the exit of the oxidizer-duct the oxidizer boundary. The reactant streams flow toward a stagnation plane. The momentum of the two streams is approximately balanced to maintain the stagnation plane at the center of the two boundaries. Fine wire screens are placed at the exits of the fuel-duct and oxidizer-duct. This makes the tangential 
component of the flow velocity negligibly small at the exit of the ducts. The mass fraction of fuel, temperature, and component of the flow velocity normal to the stagnation plane at the fuel boundary are represented by $Y_{\mathrm{F}, 1}, T_{1}$, and $V_{1}$, respectively. The mass fraction of oxygen, temperature, and component of the flow velocity normal to the stagnation plane at the oxidizer boundary are represented by $Y_{\mathrm{O}_{2}, 2}, T_{2}$, and $V_{2}$, respectively. The distance between the fuel boundary and the oxidizer boundary is represented by $L$. Critical conditions of extinction are measured with $L=10 \mathrm{~mm}$ and ignition with $L=12 \mathrm{~mm}$. The velocities of the reactants at the boundaries are presumed to be equal to the ratio of their volumetric flowrates to the cross-section area of the ducts. The temperature of the fuel stream and the temperature of the oxidizer stream at the boundaries are measured using thermocouples. The temperatures are corrected for radiation losses. The liquid fuels are vaporized in the vaporizer with the temperature monitored by a thermocouple. The flow rates of gases are adjusted by computer-regulated mass flow controllers. The flow lines are heated to prevent condensation.

The value of the strain rate, defined as the normal gradient of the normal component of the flow velocity, changes from the fuel boundary to the oxidizer boundary [8]. The characteristic strain rate on the air side of the stagnation plane $a_{2}$ is presumed to be given by [8]

$$
a_{2}=\frac{2\left|V_{2}\right|}{L}\left(1+\frac{\left|V_{1}\right| \sqrt{\rho_{1}}}{\left|V_{2}\right| \sqrt{\rho_{2}}}\right) .
$$

Here $\rho_{1}$ and $\rho_{2}$ represent the density of the mixture at the fuel boundary and at the oxidizer boundary, respectively. Equation 1 is obtained from an asymptotic theory where the Reynolds numbers of the laminar flow at the boundaries are presumed to be large [8]. Figure 2 shows a photograph 
and some details of the counterflow burner. Silicon-carbide heating elements are placed inside the oxidizer-duct to heat the air for the ignition experiments. The products of combustion flow into a region around the fuel-duct where they are cooled by water sprays. A curtain flow of nitrogen is introduced from concentric tubes placed outside the reactant ducts. Further details of the burner are given elsewhere $[9,10]$.

Critical conditions of extinction and ignition are measured that depend on the six experimental parameters of pressure, $p$, and the quantities $a_{2}, Y_{\mathrm{F}, 1}, T_{1}, Y_{\mathrm{O}_{2}, 2}$, and $T_{2}$. The experiments are carried out at atmospheric pressure. The oxidizer stream is air with $Y_{\mathrm{O}_{2}, 2}=0.233$. The temperature of the fuel stream, $T_{1}=468( \pm 10) \mathrm{K}$. This fixes three of the six parameters. The extinction experiments are carried out with $T_{2}=298 \mathrm{~K}$. At some selected value of $Y_{\mathrm{F}, 1}$ the flame is stabilized at $a_{2}<a_{2, \mathrm{e}}$. The strain rate is increased by increasing $V_{1}$ and $V_{2}$ until extinction is observed. The strain rate at extinction, $a_{2, \mathrm{e}}$, is recorded as a function of mass fraction of $Y_{\mathrm{F}, 1}$. The accuracy of the strain rate is $\pm 10 \%$ of recorded value and that of the fuel mass fraction $\pm 3 \%$ of recorded value. The experimental repeatability on reported strain rate is $\pm 5 \%$ of recorded value. The experimental results are shown later.

The ignition experiments are carried out at fixed values of $Y_{\mathrm{F}, 1}=0.4$. The flow field is established at chosen values of strain rate. The temperature of air is increased until ignition takes place. The onset of ignition is observed using a high-speed camera to make sure that ignition takes place close to the axis of symmetry. The temperature of the air stream, $T_{2, \mathrm{I}}$ is recorded as a function of the strain rate, $a_{2, \mathrm{I}}$. The accuracy of the measurement of the temperature of air at ignition is expected to be $\pm 30 \mathrm{~K}$, the strain rate $\pm 10 \%$, and fuel mass fraction $\pm 3 \%$ of recorded value. The experimental 
repeatability in the measurement of the temperature of air at ignition is expected to be $\pm 6 \mathrm{~K}$. The results are shown later.

\section{Description of the Chemical Kinetic Mechanism}

The model presented in this paper was developed from previous $n$-heptane and iso-octane $[11,12]$ and methyl butanoate mechanisms [2] by combining them with the low and high temperatures chemistry specific to methyl decanoate. In general, the reaction classes from Curran et al. [12] were used, but accommodations were required to take into account the fact that the methyl ester group in methyl decanoate changes some of the details of the mechanism.

High temperature part. At high temperatures, unimolecular decompositions of the fuel and $\mathrm{H}$ atom abstractions from the fuel lead to the formation of alkyl and alkyl-ester radicals. Reactions of these radicals, which are known to be pertinent at high temperature, are isomerizations, decompositions to olefins or unsaturated esters plus smaller radicals, and direct abstractions by $\mathrm{O}_{2}$ to olefins or unsaturated esters plus $\mathrm{HO}_{2}$. Olefins and unsaturated esters formed through these primary routes react in turn through the same types of reactions as the fuel and through other reactions specifically due the presence of the double bond (additions of radicals to the double bond, decomposition by retro-ene reactions).

H-atom abstractions from methyl decanoate by $\mathrm{H}, \mathrm{CH}_{3}, \mathrm{C}_{2} \mathrm{H}_{3}, \mathrm{C}_{2} \mathrm{H}_{5}, \mathrm{O}, \mathrm{O}_{2}, \mathrm{OH}, \mathrm{HO}_{2}, \mathrm{CH}_{3} \mathrm{O}$, and $\mathrm{CH}_{3} \mathrm{O}_{2}$ have been included, using kinetic parameters recommended by Curran et al. [12]. Distinctions between three types of $\mathrm{H}$ atoms were made: primary $\mathrm{H}$ atoms in the two methyl groups at 
each end of the molecule, secondary $\mathrm{H}$ atoms bonded to the conventional secondary, internal carbon atoms, and the two $\mathrm{H}$ atoms bonded to the carbon atom adjacent to the carbonyl group. There is a lack of data concerning the rate constants of $\mathrm{H}$-atom abstractions involving these two $\mathrm{H}$ atoms. These $\mathrm{H}$ atoms have $\mathrm{C}-\mathrm{H}$ bond energies similar to those for tertiary $\mathrm{C}-\mathrm{H}$ bonds, so we have followed [2] and used $\mathrm{H}$ atom abstraction rates from tertiary bonds in other molecules for these $\mathrm{H}$ atoms.

Alkyl and alkyl-ester radical decompositions were written in the reverse direction (addition of a radical to a double bond). Kinetic parameters are based on a recent review by Curran for the alkyl radicals [13] and from the methyl butanoate mechanism [2] for reactions involving atoms of the ester group. The kinetic parameters for addition of radicals to the oxygen of the $\mathrm{C}=\mathrm{O}$ bond have been updated from the study of methyl radical addition to the $\mathrm{C}=\mathrm{O}$ bond by Henry et al. [14]. Kinetic parameters used for isomerizations, or $\mathrm{H}$-atom shifts, of radicals were taken from quantum calculations performed by Matheu et al. [15]. Some required rate constants not calculated by these authors are estimated using "structure-reactivity" relationships.

As far as olefins and unsaturated esters are concerned $\mathrm{H}$-atom abstractions and molecular decompositions by retro-ene reactions were written in a systematic way. Rate constants for primary, secondary and tertiary $\mathrm{H}$-atoms abstractions from olefins and unsaturated esters are the same as those described above for the methyl decanoate molecule. For allylic and vinylic H-atoms, kinetic parameters are those recommended by Curran et al. [12] for small species (propene, 1-butene). The rate constant for the molecular decomposition of olefins and unsaturated esters by retro-ene reaction is from King [16]. Only unimolecular initiations involving $\mathrm{C}-\mathrm{C}$ and $\mathrm{C}-\mathrm{H}$ bonds in the beta 
position of the double bond have been taken in account. Other $\mathrm{C}-\mathrm{C}, \mathrm{C}-\mathrm{O}$ and $\mathrm{C}-\mathrm{H}$ bond breaking were not included because of their higher activation energies. Unimolecular decompositions of olefins and unsaturated esters by scission of the allylic $\mathrm{C}-\mathrm{C}$ bond were written in the forward direction and the scission of the allylic $\mathrm{C}-\mathrm{H}$ bonds in the reverse, recombination direction. Additions of $\mathrm{OH}$ radicals to the double bond of olefins and unsaturated radicals were written and additions of $\mathrm{H}$ atoms and $\mathrm{HO}_{2}$ radicals were considered in two other parts of the mechanism (alkyl and alkyl-ester radicals $\mathrm{C}-\mathrm{H} \beta$-scission decompositions in the low temperature part).

Rate constants for isomerizations of alkenyl, allylic and vinylic radicals are from [15]. Decompositions of these radicals were considered through the reverse additions and kinetic parameters are the same as those presented in the methyl decanoate section above.

Low temperature part. The low temperature part of the mechanism was built by adapting the kinetic scheme used in the well-validated $n$-heptane and iso-octane mechanisms. Again, some accommodations were required due to the presence of the methyl ester group in the fuel.

The first step of the low temperature mechanism is the addition of alkyl and alkyl-ester radicals to $\mathrm{O}_{2}$. The subsequent alkyl and alkyl-ester peroxy radicals $\left(\mathrm{RO}_{2}\right)$ react then by isomerizations to hydroperoxy alkyl and hydroperoxy alkyl-ester radicals (QOOH). Isomerizations through 5, 6, 7 and 8 member cyclic transition states have been included.

Rate constants for $\mathrm{QOOH}$ decompositions to cyclic ethers plus $\mathrm{OH}$ and to olefin plus $\mathrm{HO} 2$ are those recommended by Curran et al. [12]. Other reaction and rate constants in the low temperature 
part of the mechanism are not described here because they are not important under conditions studied here, but are described in [7].

The above described mechanism involves 3036 species and includes 8555 reactions. The high numbers of reactions and species are caused by the numerous types of reactions taken in account but also to the fact that methyl decanoate is not a symmetric molecule like an n-alkane. Isomerizations of $\mathrm{RO}_{2}$ species in the low temperature regime are also responsible for the large increase in the number of reactions because of the numerous permitted $\mathrm{H}$-shifts.

Thermodynamic properties: Standard enthalpies of formation, entropies and specific heats of the molecules and radicals involved in the mechanism have been calculated using the THERM program developed by Ritter and Bozzelli [17]. This program is based on the group and bond additivity methods proposed by Benson [18].

The $\mathrm{C}-\mathrm{H}$ bond dissociation energy of the carbon atom adjacent to the carbonyl group has been updated from the recent work of El-Nahas et al. [19] who studied the thermochemistry of methyl butanoate by performing quantum calculations. The value used in the mechanism for this specific bond is $94.1 \mathrm{kcal} / \mathrm{mol}$. This compares closely to tertiary bond dissociation energies $(96.5 \mathrm{kcal} / \mathrm{mol})$ as noted above for $\mathrm{H}$ atom abstractions from this site in methyl decanoate.

Transport properties: The transport parameters were obtained from the CHEMKIN database [20], Marinov et al. [21], and using the critical temperature and pressure from the NIST WebBook [22] and the Tee, Gotoh, Stewart correlation as stated in [23]. The transport parameters for species for 
which critical properties were not available were estimated as being the same as other species similar in size and structure.

The entire mechanism is available at Ref. [24].

\section{Mechanism Reduction of Methyl Decanoate with Directed Re-}

\section{lation Graph}

The detailed mechanism of methyl decanoate consists of 3036 species and 8555 reactions. Consequently computational simulation using this mechanism is very time consuming for 0 -D simulations such as ignition and perfectly stirred reactors (PSR), and is not affordable even for one-dimensional (1-D) simulations. Also, it is very difficult to obtain accurate solutions in 1-D reacting flows with such large detailed chemical-kinetic mechanisms. Therefore this mechanism has to be reduced before being applied to diffusive systems. The major difficulty in its reduction is the large size, for which few methods are feasible because many conventional approaches such as sensitivity analysis become unaffordable when the number of species is larger than a few hundreds. In the present study, the method of direct relation graph (DRG) [25-27] was selected to eliminate unimportant species and reactions from the detailed mechanism to obtain a skeletal mechanism that is sufficiently small for the simulation of counterflow ignition.

DRG maps the species coupling to a digraph through quantification of the relative error in one species induced by the elimination of another. Species strongly coupled to the major species, such 
as the fuel and oxidizer, can be subsequently identified through graph searching. DRG has two important features. First, the relative reduction error is controlled by a user-specifiable threshold value, such that it does not require post-reduction validation for error control. Second, it is extremely fast, rendering the method particularly suitable for very-large mechanisms.

The reduction of the detailed mechanism with DRG was performed on a set of reaction states sampled from representative applications, specifically ignition for ignition chemistry and PSR for steady burning and extinction. The sampled space consists of more than 3000 reaction states, densely covering the entire parameter range of interest, specifically atmospheric pressure, equivalence ratio from 0.5 to 1.5 , initial temperature $900-1300 \mathrm{~K}$ for ignition and $300 \mathrm{~K}$ for PSR, and $\mathrm{N}_{2}$ diluted air with mole fraction for $\mathrm{O}_{2}$ from 0.19 to 0.21 . The sampling process was performed in parallel on a 16-node PC cluster, taking about one day. The reduction based on the entire sample space took about 20 minutes on a single P4 CPU.

Figure 3 shows the number of species in the resulting skeletal mechanisms as a function of the relative reduction error. It is seen that the slope of the reduction curve is steep for small error tolerances, indicating that a large number of species can be eliminated with only minor induced error. For example, a skeletal mechanism with 125 species and 713 elementary reactions was obtained with a reduction error of about $20 \%$. This skeletal mechanism is sufficiently small and will be employed in the 1-D simulations of counterflow ignition and extinction in the following sections.

The skeletal chemical-kinetic mechanism is available at Ref. [24] and as supplemental data. 


\section{Results and Discussion}

The skeletal chemical-kinetic mechanism was used to compute critical conditions of ignition, and the results were compared to the experiments. Figure 4 shows the mass fraction of fuel, $Y_{\mathrm{F}, 1}$, as a function of the strain rate at extinction, $a_{2, \mathrm{e}}$. The symbols in this figure represent experimental data. They separate a flammable region for $a_{2}<a_{2, \mathrm{e}}$ from a nonflammable region for $a_{2}>a_{2, \mathrm{e}}$. Figure 5 shows the temperature of air at ignition, $T_{2, \mathrm{I}}$, as a function of the strain rate, $a_{2}$ for fixed values of $Y_{\mathrm{F}, 1}=0.4$. The symbols represent experimental data. The line in Figure 5 represents results of numerical calculations using the skeletal chemical-kinetic mechanism. It separates a region for $T_{2}>T_{2, \mathrm{I}}$ where ignition can take place from a region where ignition is not possible. For a given $a_{2}$ the calculated value of $T_{2, \mathrm{I}}$ is higher than the measured value by about $35 \mathrm{~K}$. The agreement between numerical calculations and experimental data is considered to be reasonably good.

The mechanism reduction process helped identify the importance of different reactions in the counterflow flame under conditions of ignition and extinction. In the reduction process, calculations of zero-dimensional (0-D) ignition states and 0-D PSR states were used to retain the chemistry important for ignition and extinction in the counterflow system. One of the most interesting features is that the reduction process found the low temperature chemistry to be of little importance under these counter flow conditions. The only reaction retained involving radicals produced directly from the fuel was $\mathrm{R}+\mathrm{O}_{2}=\mathrm{RO}_{2}$ where $\mathrm{R}$ is the radical with an $\mathrm{H}$ removed from the carbon next to the carbonyl group. There were also four other low temperature reactions retained involving the same reaction and moiety from the methyl propanoate and methyl ethanoate molecules, and the 1-heptyl and 1-octyl radicals. Subsequently the radicals with ester moieties then isomerize and produce 
cyclic ethers and reactive $\mathrm{OH}$ radicals.

On the other hand, the chemistry retained by the reduction process were the fuel decomposition reactions, and the abstraction of $\mathrm{H}$ atoms from the fuel by $\mathrm{OH}, \mathrm{H}, \mathrm{O}, \mathrm{HO}_{2}, \mathrm{CH}_{3}$ etc. The following reactions retained were the decomposition of fuel radicals, reaction of fuel radicals with $\mathrm{O}_{2}$ to make olefins, and isomerization of fuel radicals. The main intermediates with ester moieties that were kept also had olefinic structures: methyl butenoate and methyl propenoate. These are "olefins" derived from the decomposition of the methyl decanoate radicals and their decomposition products. Comparing methyl ester fuels with alkane fuels, these intermediates correspond to olefins like butene and propene derived from alkane fuels. The formation of these olefins with ester moieties is consistent with the experimental observations of Dagaut et. al. [28].

\section{Concluding Remarks}

The DRG method is a very powerful technique that could be employed to simplify detailed chemicalkinetic mechanism. It was used here to obtain a skeletal chemical-kinetic mechanism for describing combustion of methyl decanoate from a detailed chemical-kinetic mechanism. Simulations of igni-

tion in 0-D systems as well as simulations of steady burning and extinction in PSR carried out using the skeletal mechanism agree well with those calculated using the detailed mechanism. Predictions of ignition of methyl decanoate in nonpremixed flows obtained using the skeletal mechanism agree with experimental data. For a given value of the mass fraction of fuel in the fuel stream, the strain rate at extinction calculated using the skeletal chemical-kinetic mechanism is significantly lower than the measurements. Therefore there is a need to improve the chemical-kinetic mechanism so 
that it can better predict extinction in diffusive systems. The derived skeletal mechanism shows that low temperature chemistry is of minor importance under the counterflow conditions considered. The reaction chemistry of most importance are the high temperature reactions of fuel decomposition, radical abstraction, isomerization, and radical decomposition. Formation and consumption of olefin intermediates with ester moieties were also found to be significant.

\section{Acknowledgment}

The research at the University of California at San Diego is supported by UC Discovery/Westbiofuels, Grant \# GCP06-10228. The work at Princeton University was supported by the Air Force Office of Scientific Research under the technical monitoring of Dr. Julian M. Tishkoff. The work at LLNL was supported by the U. S. Department of Energy, Office of the Freedom CAR and Vehicle Technologies, program manager Kevin Stork and Gurpreet Singh, and performed under the auspices of the U. S. Department of Energy by Lawrence Livermore National Laboratory under Contract DE-AC52-07NA27344. 


\section{References}

[1] S. Gä̈l, M. Thomson, S. Sarathy, S. Syed, P. Dagaut, P. Diévart, A. Marchese, F. Dryer, Proceedings of the Combustion Institute 31 (2007) 305-311.

[2] E. M. Fisher, W. J. Pitz, H. J. Curran, C. K. Westbrook, Proceedings of the Combustion Institute 28 (2000) 1579-1586.

[3] S. Sarathy, S. Gä̈l, S. Syed, M. Thomson, P. Dagaut, Proceedings of the Combustion Institute 31 (2007) 1015-1022.

[4] P. Dagaut, S. Gaïl, M. Sahasrabudhe, Proceedings of the Combustion Institute 31 (2007) 29552961.

[5] J. P. Szybist, A. L. Boehman, D. C. Haworth, H. Korga, Combustion and Flame 149 (2007) $112-128$.

[6] J. A. Szybist, J. Song, M. Alam, A. L. Boehman, Fuel Processing Technology 88 (2007) 679_ 691.

[7] O. Herbinet, W. J. Pitz, C. K. Westbrook, K. D. King, Combustion and Flame (2007) submitted.

[8] K. Seshadri, F. A. Williams, International Journal of Heat and Mass Transfer 21 (2) (1978) $251-253$.

[9] R. Seiser, L. Truett, D. Trees, K. Seshadri, Proceedings of the Combustion Institute 27 (1998) $649-657$. 
[10] R. Seiser, K. Seshadri, E. Piskernik, A. Liñán, Combustion and Flame 122 (2000) 339-349.

[11] H. J. Curran, P. Gaffuri, W. J. Pitz, C. K. Westbrook, Combustion and Flame 114 (1998) $149-177$.

[12] H. J. Curran, P. Gaffuri, W. J. Pitz, C. K. Westbrook, Combustion and Flame 129 (2002) 253-280.

[13] H. J. Curran, International Journal of Chemical Kinetics 38 (4) (2006) 250-275.

[14] D. J. Henry, M. L. Coote, R. Gomez-Balderas, L. Radom, Journal of the American Chemical Society 126 (6) (2004) 1732-1740.

[15] D. M. Matheu, W. H. Green, J. M. Grenda, International Journal of Chemical Kinetics 35 (3) (2003) 95-119.

[16] K. D. King, International Journal of Chemical Kinetics 11 (10) (1979) 1071-1080.

[17] E. R. Ritter, J. W. Bozzelli, International Journal of Chemical Kinetics 23 (9) (1991) 767-778.

[18] S. W. Benson, Thermochemical Kinetics, 2nd Edition, John Wiley, New York, 1976.

[19] A. M. El-Nahas, M. V. Navarro, J. M. Simmie, J. W. Bozzelli, H. J. Curran, S. Dooley, W. Metcalfe, Journal of Physical Chemistry A 111 (19) (2007) 3727-3739.

[20] R. J. Kee, J. Warnatz, J. A. Miller, A Fortran Computer Code Package for the Evaluation of Gas Phase Viscosities, Conductivities and Diffusion Coefficients, Tech. Rep. SAND83-8209, Sandia National Laboratories, Livermore, CA (1983). 
[21] N. M. Marinov, W. J. Pitz, C. K. Westbrook, A. E. Lutz, A. M. Vincitore, S. M. Senkan, Proceedings of the Combustion Institute 27 (1998) 605-613.

[22] NIST Standard Reference Database Number 69, NIST Chemistry WebBook (2003).

[23] L. S. Tee, S. Gotoh, W. E. Stewart, Industrial \& Engineering Chemistry 5 (3) (1966) 356-363.

[24] http://www-cmls.llnl.gov/?url=science_and_technology-chemistry-combustion.

[25] T. F. Lu, C. K. Law, Proceedings of the Combustion Institute 30 (2005) 1333-1341.

[26] T. F. Lu, C. K. Law, Combustion and Flame 144 (2006) 24-36.

[27] T. F. Lu, C. K. Law, Combustion and Flame 146 (2006) 472-483.

[28] P. Dagaut, S. Gä̈l, Journal of Physical Chemistry A 111 (19) 3992-4000. 


\section{List of Figures}

1 Schematic illustration of the counterflow flow field. . . . . . . . . . . . . 19

2 A photograph of the counterflow burner and a sketch of the reactant flow in the ducts 20

3 Number of species in skeletal mechanisms as a function of the threshold error specified in the reduction with directed relation graph, based on sampled reaction states from ignition and PSR. . . . . . . . . . . . . . . . . 21

4 The mass fraction of fuel, $Y_{\mathrm{F}, 1}$, as a function of the strain rate at extinction, $a_{2, \mathrm{e}}$. The symbols represent experimental data. . . . . . . . . . . . . . . 22

5 The temperature of the oxidizer stream at ignition, $T_{2, \mathrm{I}}$, as a function of the strain rate, $a_{2}$ for $Y_{\mathrm{F}, 1}=0.4$. The symbols represent experimental data. The line is result of numerical calculations using the skeletal chemical-kinetic mechanism. . . . . . 23 


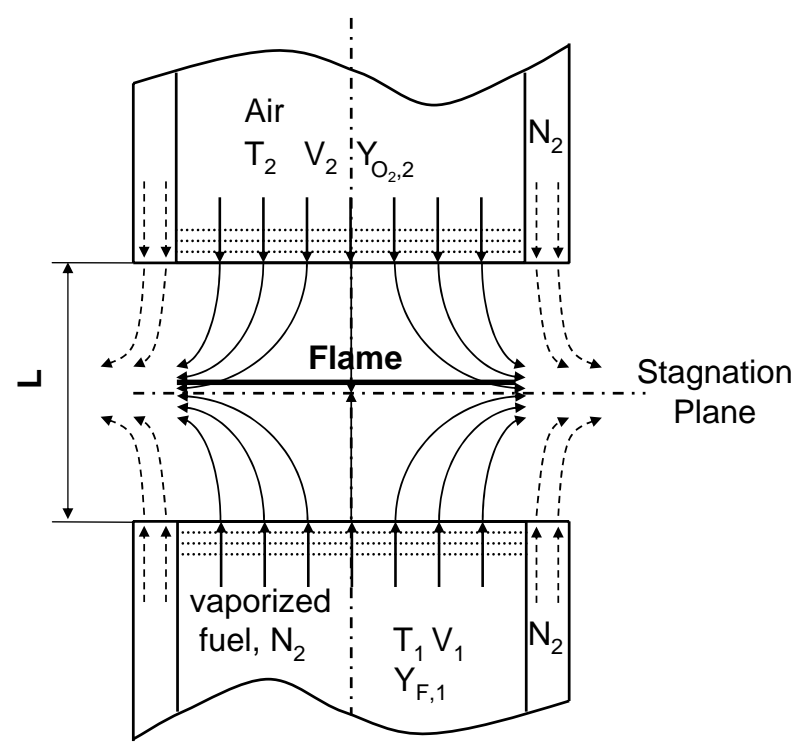

Figure 1: Schematic illustration of the counterflow flow field. 

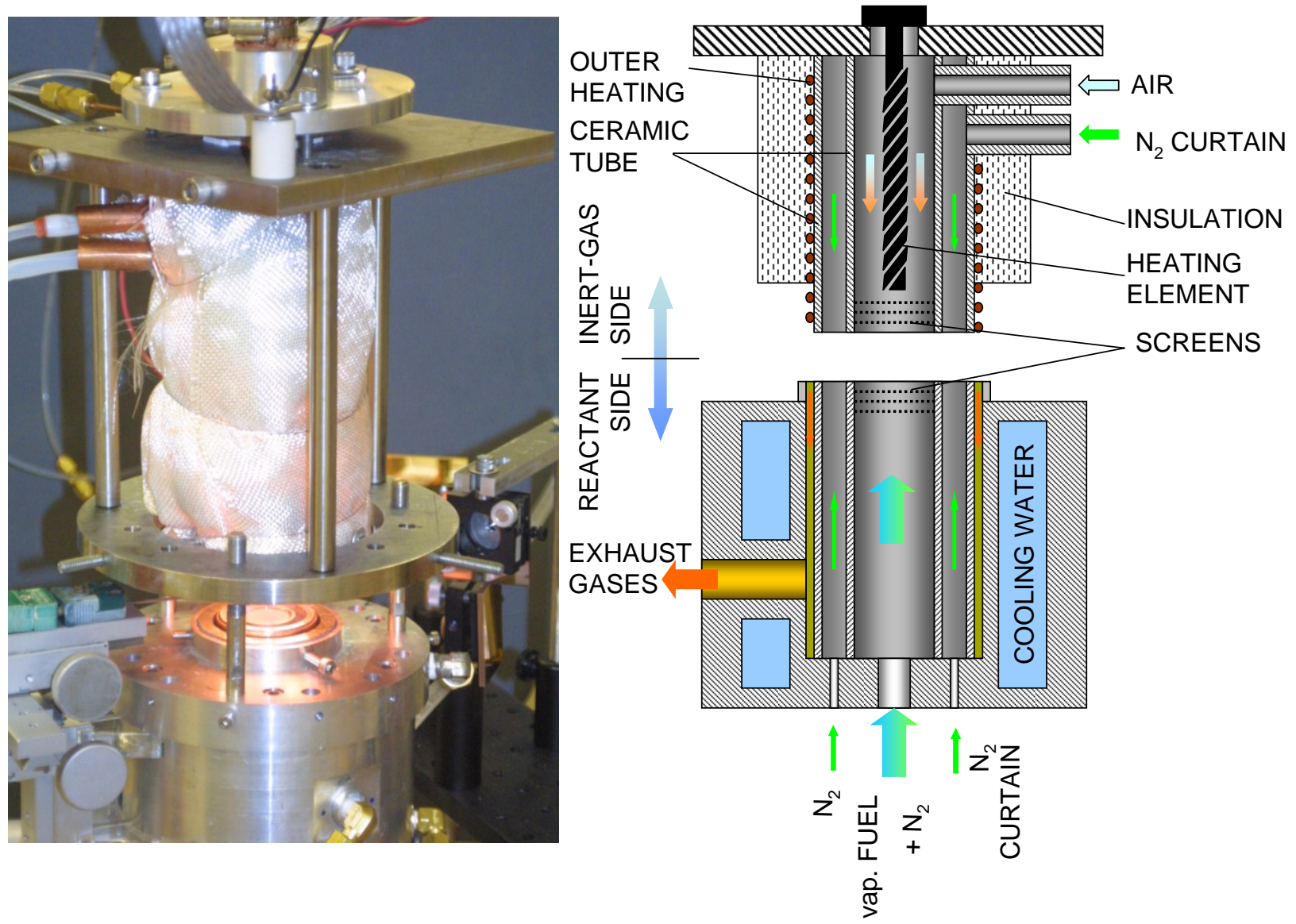

Figure 2: A photograph of the counterflow burner and a sketch of the reactant flow in the ducts 


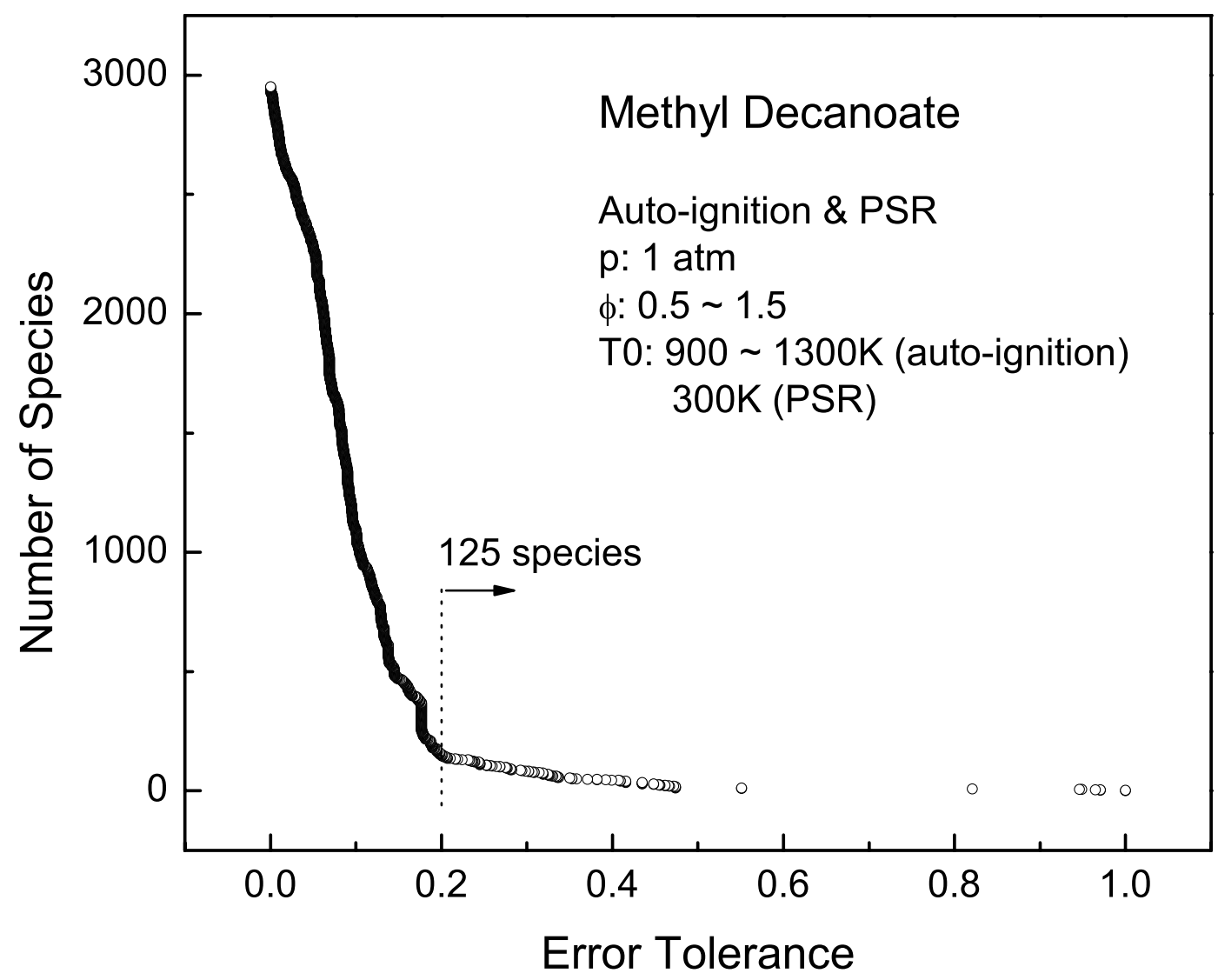

Figure 3: Number of species in skeletal mechanisms as a function of the threshold error specified in the reduction with directed relation graph, based on sampled reaction states from ignition and PSR. 


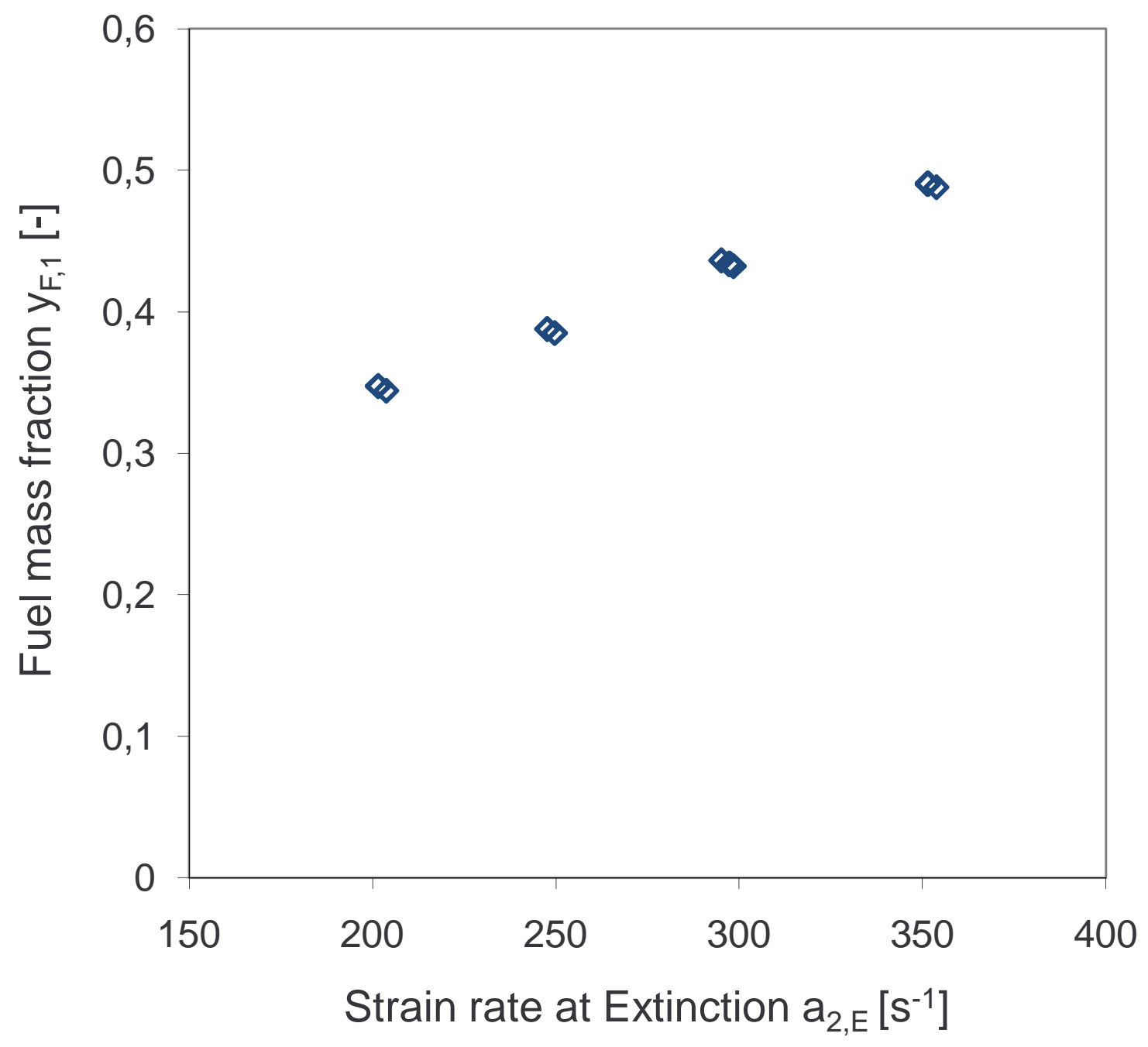

Figure 4: The mass fraction of fuel, $Y_{\mathrm{F}, 1}$, as a function of the strain rate at extinction, $a_{2, \mathrm{e}}$. The symbols represent experimental data. 


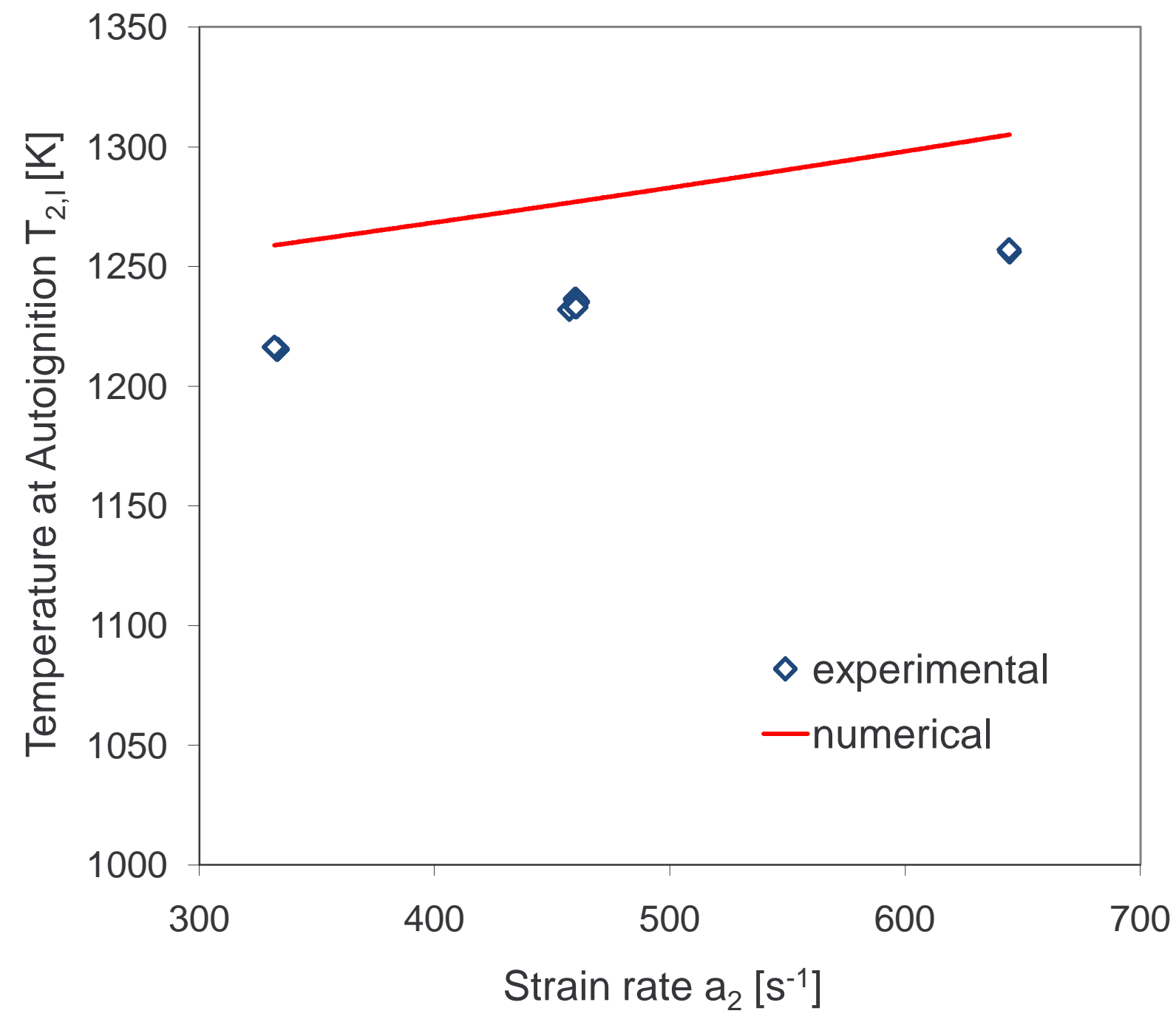

Figure 5: The temperature of the oxidizer stream at ignition, $T_{2, \mathrm{I}}$, as a function of the strain rate, $a_{2}$ for $Y_{\mathrm{F}, 1}=0.4$. The symbols represent experimental data. The line is result of numerical calculations using the skeletal chemical-kinetic mechanism. 
Supplemental Material
Click here to download Supplemental Material: md_red_mech_v1.txt t

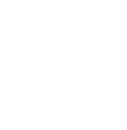
(2)

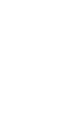

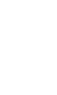

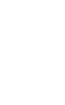

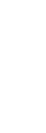

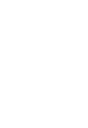

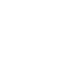

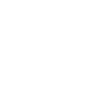
更

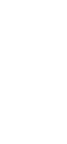
西 $x^{2}+n^{2}$

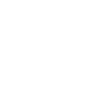


Supplemental Material
Click here to download Supplemental Material: md_therm_v1.txt

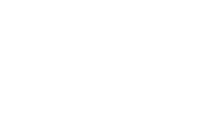

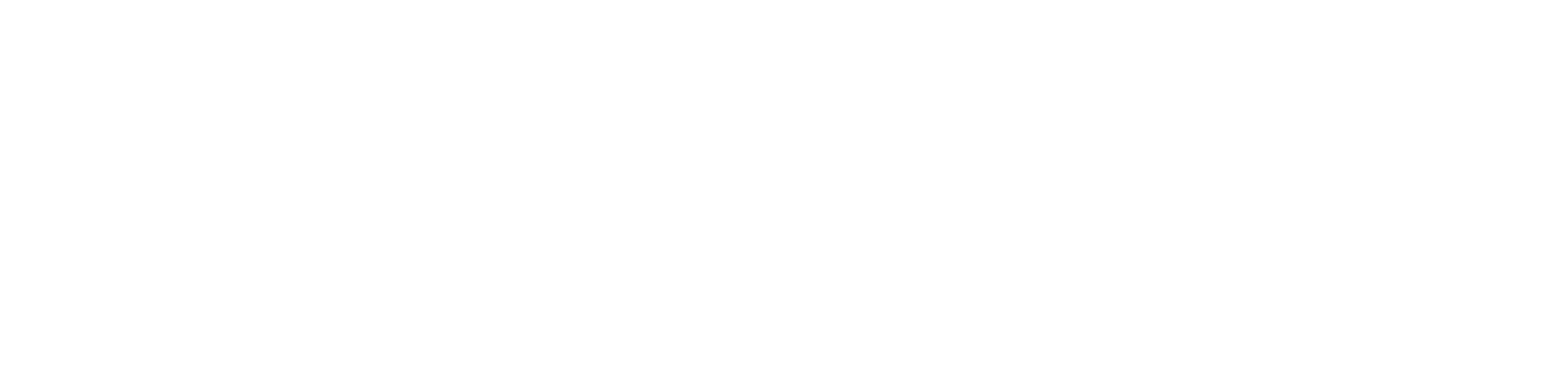

cor

cor

cor

cor

cor

cor

(2)

(1)

(1)

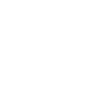

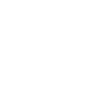

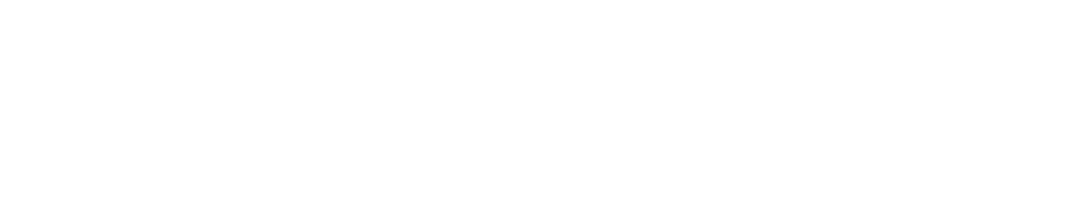


Supplemental Material
Click here to download Supplemental Material: md_tran_v1.txt

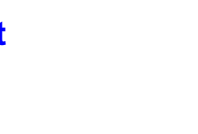
(a)

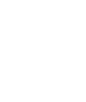

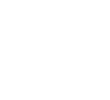
(1) (n)

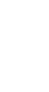

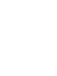

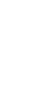

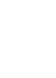

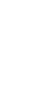

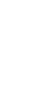
(1)

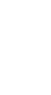

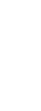
(n) . . .

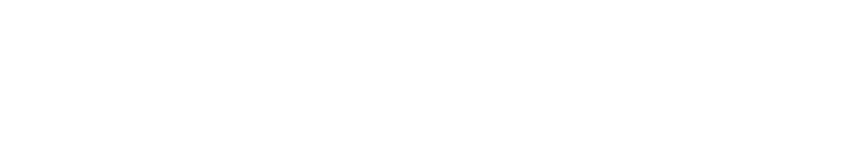

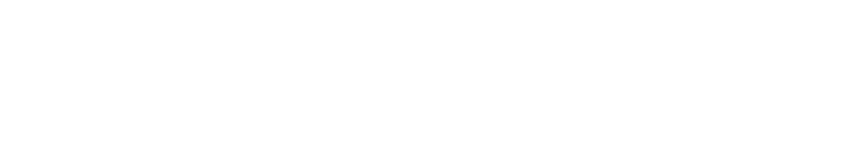

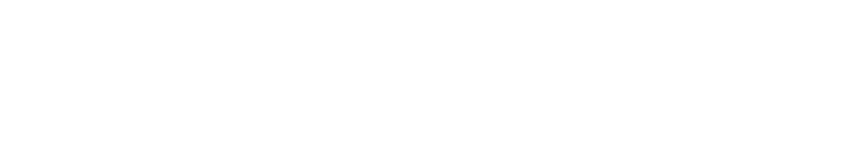

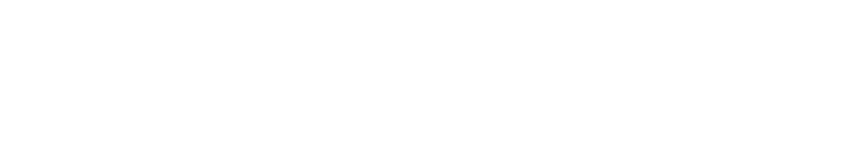

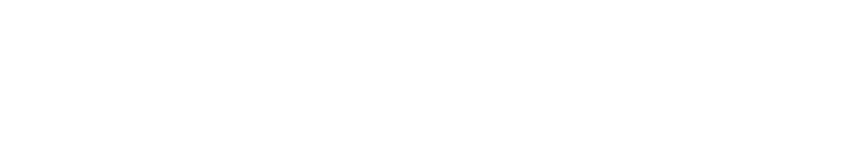

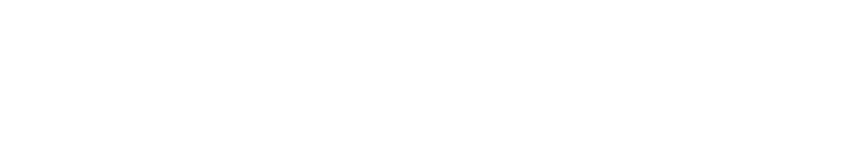
(1) (1) (1) (1) (1) (1) (1) (1) (1) (1) (1) (1) (1) (2) (1) (1) (1) (1) (1) (1) (1) (1) (1)

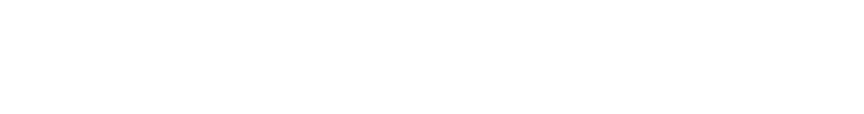
. .

.

